we assessed weight, height, BMI and z-BMI at diagnosis and 1 year later. We also investigated the compliance with the prescribed food program and GFD, then selecting only patients with strict adherence to GFD, and subdividing them into 2 groups: A (balanced diet) and $\mathrm{B}$ (non-controlled diet).

Results The characteristics of $\mathrm{A}$ and $\mathrm{B}$, as in Tab.1, show a reduction of $z$-BMI $(\Delta z-B M I=-0.49 \pm 0.41)$ in all patients of group $A$, while in group $B(\Delta z-B M I=-0.28 \pm 0.54)$ the $z$-BMI increased in 2 cases and reduced in 6 , but less than in $A$.

Conclusions Probably due to the small number of cases, the differences in the z-BMI changes between OCC with a balanced GFD and those with a non-controlled GFD are not significant. Nonetheless, we assert that is fundamental that these patients follow ad adequate diet, especially to avoid the worsening of a state of malnutrition in excess, often already present at the diagnosis.

Abstract 1418 Table 1

\begin{tabular}{llllll}
\hline & $\begin{array}{l}\text { Age at } \\
\text { diagnosis }\end{array}$ & $\begin{array}{l}\text { z-BMI at } \\
\text { diagnosis }\end{array}$ & $\begin{array}{l}\text { z-BMI at } \\
\text { follow-up }\end{array}$ & $\Delta$ z-BMI & $\begin{array}{l}\text { follow-up } \\
\text { lenght }\end{array}$ \\
\hline A group (4M and 4F) & $11.35 \pm 3.79$ & $1.93 \pm 0.69$ & $1.44 \pm 1.01$ & $-0.48 \pm 0.41$ & $11.62 \pm 1.68$ \\
B group (3M and 5F) & $9.12 \pm 4.26$ & $1.86 \pm 0.53$ & $1.57 \pm 0.96$ & $-0.28 \pm 0.54$ & $12.62 \pm 1.60$ \\
\hline
\end{tabular}

1419 OBESITY AND BINGE EATING DISORDER IN CHILDHOOD: AN INTEGRATED THERAPEUTIC APPROACH

doi:10.1136/archdischild-2012-302724.1419

A Macari, B De Marco, M Margiotta, AR Mazzotta, C Casini, ME Liverani, MP Villa. Sapienza University of Roma, Roma, Italy

Background Binge Eating Disorder (BED) is related to obesity in children; treatment of obesity could be improved by using either a nutritional and psychotherapeutic strategy.

Aims To assess the prevalence of BED and weight trend in an overweight or obese pediatric population; to evaluate an Integrated Therapeutic Approach (ITA) in a BED positive group.

Methods Ninenty-seven subjects (M/F 53/44, mean age $11.0 \pm 2.4$ $y r$, range $6.1-16.2)$ with overweight $(M / F$ 8/18) or obesity $(M / F$ 45/26) undergone physical examination, body weight, waist and hip circumference and blood pressure. A Binge Eating Scale (BES) to evaluate BED (positive>17) was used. All BED-positive patients were asked for a normocaloric diet for age and regular physical activity for at least an hour a day and followed with monthly checks; six BED-positive children undergone both medical visits and 10 sessions of psychotherapy (ITA). BED was evaluated before and after psychotherapy.

Results BED was found in 29/97 (29.9\%) subjects, of whom 20 $(69 \%)$ had a BMI $>95^{\text {th }}$ percentile. BMI did not change in the six BED-positive children followed with ITA nor in a matched group of six BED-positive children followed without ITA ( $3 / 6$ dropped-out). Instead, ITA reduced gravity of BED in all patients and negativized $(\mathrm{BES}<17)$ in four patients.

Conclusions Early improvements in BED can be achieved with an integrated therapeutic approach as a first step for long-term reduction of obesity.

\section{EXAMINATION OF THE RELATION OF DIET AND PHYSICAL ACTIVITY WITH THE APPEARANCE OF OBESITY AT GREEK STUDENTS}

doi:10.1136/archdischild-2012-302724.1420

${ }^{1} \mathrm{~K}$ Kyriazis, ${ }^{1} \mathrm{~K}$ Bakalakou, ${ }^{2} \mathrm{M}$ Rekleiti, ${ }^{3} \mathrm{M}$ Saridi, ${ }^{4} \mathrm{P}$ Kyloudis, ${ }^{5}$ loannidis. ${ }^{12}$ nd Internal Medicine Department \& Diabetes Outpatient Clinic, Asclepeion General Hospital, Athens; ${ }^{2}$ General Hospital of Korinthos; ${ }^{3}$ Nursing, General Hospital of Korinthos, Korinthos; ' General Hospital 'G. Papanikolaou', Thessaloniki; '5iabetes and Obesity Outpatient Clinic, Konstantopoulion General Hospital N. Ionia, Athens, Greece
Background Childhood obesity increases the likelihood of several consequences for a child (precocious puberty, polycystic ovary syndrome, diabetes mellitus type 2, etc) and also later in adulthood (increased mortality due to cardiovascular disease, diabetes mellitus, etc).

Aim The aim of the current study was to investigate the prevalence of overweightness and obesity among Greek students and to determine the correlation between diet and physical activity.

Methods 2374 pupils in primary education were considered for the study (1206 boys and 1168 girls). Statistical analyses were performed using SPSS version 15.0 (SPSS Chicago, IL USA). A p-value $<0.05$ was accepted for statistical significance.

Results Cross-correlation between overweight and obese children and sex showed that more males $(9.2 \%)$ are obese than females $(5.3 \%)$. The rate of overweight children was at $23.9 \%$, of obese children at $7.3 \%$ and the rate of central obesity was at $35.5 \%$. Regarding children that did not follow a healthy diet in school, $34.1 \%$ of them were overweight or obese and $38.6 \%$ had central obesity; $32 \%$ of the children that had a healthy diet in school were overweight or obese, and $27.8 \%$ of them had central obesity. In multiple regression analyses, central obesity was associated with hours of daily TV watching and with the hours of daily computer use.

Conclusions It is important adhering to a healthy lifestyle which emphasizes healthy food choices and habits, regular physical activity, and limiting screen time.

\section{THE IMPORTANCE OF IR-HOMA AND WTHR IN THE PREDICTION OF THE DEVELOPMENT OF METABOLIC SYNDROME (MS)}

doi:10.1136/archdischild-2012-302724.1421

${ }^{1} \mathrm{~A}$ Grimaldi, ${ }^{1} \mathrm{~A}$ Mosca, ${ }^{2} \mathrm{~A}$ Piedimonte, 'D Guttadoro, 'M Podagrosi, 'R Mercurio, 'A Giacomini, 'AM Caiazzo, 'RE Papa, 'A Vania. 'Dept of Paediatrics and Paediatric Neuro-Psychiatry; ${ }^{2}$ Institute of Nutrition, 'Sapienza' University of Rome, Rome, Italy

Background and Aim Globesity has made visible the increased risk, yet among youngsters, of cardiovascular diseases, NAFLD, MS.

The Aim of this study is to stress how two simple indexes (IRHOMA and $\mathrm{WtHR}_{(3)}$ ) can be useful at out-patients level to detect the presence of an often still unidentified MS.

Methods 857 ow/ob children (405 female, 47.26\%), aged 10.54 \pm 2.87 , were included in this retrospective (5 years) study

Results The standard risk factors of MS (NCEP ATP III modified) in the studied population were represented as follows: Waist Circumference $\geq 90^{\circ} \mathrm{C} 62.40 \%$; Hypertension $21.52 \%$; Triglycerides $>95^{\circ} \mathrm{C} 12.34 \%$, $\mathrm{HDL}<5^{\circ} \mathrm{c} 5.52 \%$, Glycaemia $\geq 100 \mathrm{mg} / \mathrm{dl} 4.72 \%$; besides, $34.64 \%$ showed IR-HOMA $>2.5$. The overall MS prevalence was $5.49 \%$.

Due to an $\mathrm{OR}=5.29(\mathrm{p}<0.05)$ for IR-HOMA vs. MS factors, all patients with an IR-HOMA $>2.5$ are very likely to have 3 or more elements of MS. If both IR-HOMA and WtHR are abnormal, OR becomes $6.24(\mathrm{p}<0.05)$.

Conclusions In the ow/ob child, IR-HOMA and WtHR are important anticipating factors of MS, even at a very young age, much below the age of 10 , presently considered the lowest age to diagnose such complication. This stresses once again how, in any case of obesity, an early intervention is needed, in order to prevent the development of cardiovascular disease in early adult age. ${ }_{(1)}$

1. Monereo Megías S et al. Endocrinologia y Nutricion, 2012 59:155-159.

2. Saffari F et al. Therapy Clinical Risk Managment. 2012. 8:55-63

3. Maffeis C et al. J Pediatr. 2008; 152:207-13. WEIGHT GAIN (GWG), CULTURAL LEVEL (CL), BIRTH WEIGHT (BW) AND OVERWEIGHT/OBESITY (OW/OB) OUTCOME

doi:10.1136/archdischild-2012-302724.1422 